Available online at:

www.4open-sciences.org

\title{
Solar air drying for innovative Opuntia ficus-indica cladode dehydration
}

\author{
Rosaria Ciriminna ${ }^{1}$, Vincenzo Morreale ${ }^{2}$, Mario Pecoraino ${ }^{3}$, Mario Pagliaro ${ }^{1, *}$ \\ ${ }^{1}$ Istituto per lo Studio dei Materiali Nanostrutturati, CNR, via U. La Malfa 153, 90146 Palermo, Italy \\ 2 Bioinagro, via G. Garibaldi 225 E2, 92027 Licata, AG, Italy \\ 3 via C. Giaquinto 14, 90135 Palermo, Italy
}

Received 3 June 2018, Accepted 21 January 2019

\begin{abstract}
Providing a case study of general applicability in all world's semi-arid regions where the plant is increasingly harvested, we describe the use and outcomes of solar air heating and ventilation coupled to a conventional kiln to dehydrate Opuntia ficus-indica cladodes. For the first time, the dried cladodes and the ground dehydrated 'Nopal' cladodes retain their natural green-yellow color. New applications to functionalize foodstuff and to formulate nutraceutical, personal care and cosmetic products of even higher efficacy and broader scope are anticipated.
\end{abstract}

Keywords: Opuntia ficus-indica, Cladodes, Solar drying, Nopal, Bioeconomy

Owing to its exceptional water-utilization efficiency Opuntia ficus-indica (OFI) is a cactus pear ideally suited to feed livestock in semi-arid $(250-450 \mathrm{~mm}$ annual precipitation) and even more in arid $(<250 \mathrm{~mm}$ annual precipitation) areas of the world [1]. The heavy $(>1.3 \mathrm{~kg} /$ cladode) cladophylls indeed are able to accommodate up to 93 wt.\% water [2]. Both the OFI fruits and the cladodes contain a number of phytochemicals of significant nutraceutical importance [3]. Rich in dietary fiber, carbohydrates, antioxidants, flavonoids, minerals and vitamins [4], the cladodes are a popular Mexican food consumed fresh (as young cladodes called nopalitos), cooked, dried or as juice [5]. Furthermore, cladode extracts have been used in the traditional medicine of many countries, from Mexico through Morocco, for treatment of diabetes mellitus, digestive system diseases, kidney and urinary infections [6].

In a thorough review focusing on the chemistry and uses of Opuntia cactus stems (the cladodes), Stintzing and Carle in 2005 were finding that the vegetative parts of Opuntia spp. plants was still "scarcely used in modern nutrition and medicine" [7] calling for new research "to get an insight into the multitude of bioactivities reported in the traditional literature but also to take advantage of the respective constituents for food and pharmaceutical applications" [7].

In the subsequent decade, plentiful research activities followed across the world and today the slightly brown powder (often called Nopal) obtained by grinding

\footnotetext{
*Corresponding author: mario.pagliaro@cnr.it
}

dehydrated Opuntia's cladodes is a functional ingredient widely employed to functionalize foodstuff and to formulate nutraceutical, personal care and cosmetic products [6].

Besides water, the main constituents of OFI cladodes are fiber $(4-6 \%)$, protein $(1-2 \%)$, and pectin $(0.8-3.3 \%)$ depending on the species. They also contain minor yet important amounts of phytochemicals such as phenolic compounds and flavonoids, carotenoids, chlorophyll, polyunsaturated fatty acids well as short-chain acetic, propionic and butyric fatty acids $[7,8]$.

About half of the Nopal dry powder mass is insoluble dietary fiber [9], whose consumption provides several benefits to the human gastrointestinal (digestive) tract and reduces the risk of diabetes, obesity, coronary heart disease, and certain forms of cancer. The soluble fraction mostly consists of mucilage [10] (Fig. 1) and cell-wall pectin [11]. Both are heteropolysaccharides acting as natural hydrocolloids, i.e. absorbing and concentrating water molecules at their surface and quickly increasing viscosity in solution.

Reporting new findings on the influence of cultivar and harvest month on the nutritional content of Opuntia's cladode mucilage extracts, scholars in South Africa lately emphasized how "cactus pear mucilage is a promising hydrocolloid that could replace unwanted ingredients in functional food products presenting a rare opportunity for the commercial cultivation of cactus pears in arid and semi-arid areas" [13].

Indeed, to cite just one selected recent application in food science and technology, addition of cladode powder to 


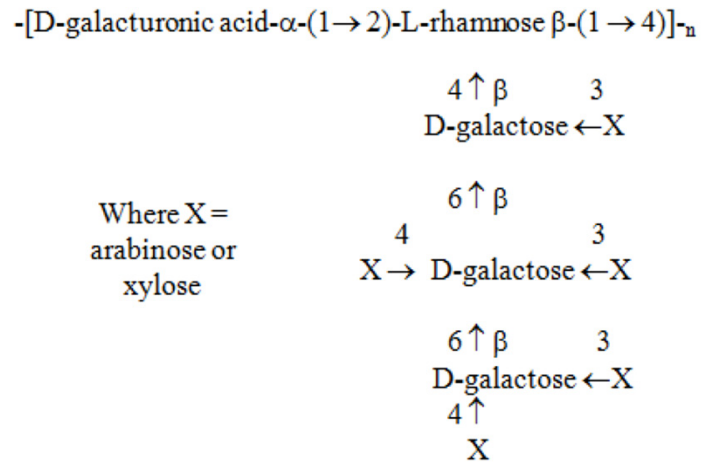

Fig. 1. Chemical structure of mucilage from Opuntia ficusindica cladodes. [Adapted from Ref. [12], with kind permission].

wheat flour at $5 \%$ level improves the total phenolics content and the antioxidant potential of bread without having any negative effect on the functionalized bread taste and texture [14].

Besides the harvesting month, numerous other agronomic and environmental factors directly affect the cladode composition [6]. For example, whereas in Sicily's OFI cladodes a total of $36 \%$ of the dry weight of whole cladodes was found to be carbohydrate [15], the level of carbohydrates in dry cladodes of OFI grown in Spain was reported between $64 \%$ and $71 \%$ [16].

Similarly, the cladodes from Ficodindia di San Cono (Opuntia ficus-indica) were lately found to be low in protein $(0.58 \%)$ and lipid $(0.12 \%)$, and particularly abundant in dietary fiber $(3.42 \%)$, with an high amount of soluble dietary fiber content $(2617 \mathrm{mg} \beta$-glucan equivalents $/ \mathrm{kg}$ ) [17]. For comparison, whereas the amount of antioxidant biophenols in OFI cladodes lately collected and analyzed in Spain was $1.7 \mathrm{~g} / \mathrm{kg}$ [18], the total phenolics content found in the San Cono OFI cladodes was $2.6 \mathrm{~g} / \mathrm{kg}$ [17].

Today's applications of Nopal as functional and health-promoting ingredient in foodstuffs include fiberrich foods, weight control products and dietary supplements [6].

Usually pure Nopal powders are colored in light brown. Selected prices found on the Word Wide Web range in wide range from $\$ 180$ for $5 \mathrm{~g}$ (Extrasynthese, France) [19] through $\$ 17.67$ for $1 \mathrm{lb} \quad(1 \mathrm{lb}=453.6 \mathrm{~g}) \quad$ (Starwest Botanicals, California) [20]. A simple search for "nopal cactus powder" carried out at the end of May 2018 on a well known online commerce platform returned 51 different products. Most are comprised of the cladode powder packaged, but capsules are also frequent [21].

The cladode powder, furthermore, is used to formulate several cosmetic and personal care products such as skincare and make-up products as it protects skin cells by limiting the formation of free radicals, decreasing the production of melanine caused by UV, and by limiting the production of cytokins produced by aggressed epidermis cells [6].

For instance, one recent clinical trial carried out with a concentration of $0.1 \%$ of $100 \%$ cells in powder [22], led to a
$31 \%$ reduction of the total surface of face wrinkles, a $14 \%$ decrease of melanin rate formation (decreasing pigmentation) and a 18\% reduction in UV-induced oxidation (along with an increase of the skin immune defense system.

Traditionally, Nopal flour has been obtained by direct sun-drying of cactus cladodes sliced and left in the open environment for several days, followed by grinding the dehydrated cladodes and sieving. Cactus pear products, indeed, are notoriously difficult to dry because of the high mucilage content. Though still used in some regions, this method, which exposes the cladodes to animals, insects, bird droppings and microbiological infestation, has been replaced by tunnel or fluid bed drying [6].

The process is typically carried out at $65-70^{\circ} \mathrm{C}$ for $72 \mathrm{~h}$ under controlled conditions in indoor processing facilities where the sliced pads are dehydrated by hot air obtained burning fossil fuels, and preferably natural gas (whose fumes are less toxic and considerably less smelling when compared to those generated burning biomass or diesel fuel) [6].

Besides high consumption of fossil fuels, the fossil-fuel driven process also poses microbiological risks because certain Opuntia's spore forming bacteria are activated at $>65^{\circ} \mathrm{C}$. Indeed, the best Nopal powder products are usually organically certified and are delivered to customers with chemical and microbiological analyses [6].

We decided, therefore, to use solar air heating to innovate Opuntia ficus-indica cladode drying. Today solar crop drying systems are widely used across the world's sunniest countries to dehydrate crops improving crop product quality meeting the increasing demand of healthy natural foods at affordable cost [23]. The technology, which is also increasingly used to heat buildings [24], dramatically reduces or even eliminates fossil energy consumption affording numerous other advantages over direct sun-drying.

A new solar dryer system comprised of six solar collectors of rectangular shape $(1.05 \mathrm{~m} \times 6.0 \mathrm{~m})$ was therefore installed in front of a conventional drying kiln conventionally used to dry tobacco leaves (De Cloet, Italy) facing directly south with no shading and tilted $60^{\circ}$ (Fig. 2).

Each collector's useful surface is $6.2997 \mathrm{~m}^{2}$ for an overall system surface of $37.798 \mathrm{~m}^{2}$. The absorber is comprised of aluminum made black through galvanic chrome plating (from trivalent chromium solutions) affording a solar selective coating of higher absorptivity and thermal conductivity, low emissivity and pronounced resistance to UV light [25].

The glazing consists of a $10 \mathrm{~mm}$ thick honeycomb polycarbonate sheet (structure: 7 walls, 6 chambers) namely an highly transparent material much lighter, impact resistant and heat insulating than glass, whose external layer exposed to sunlight has been co-extruded with a UV-resistant coating.

In Sicily's San Cono area where the array has been installed the average yearly amount of power expected to reach out the collector is esteemed to be $1670 \mathrm{~kW} / \mathrm{m}^{2}$ (Enea, Italian Atlas of Solar Radiation) which translates into $63,122 \mathrm{~kW}$ for the entire system. 


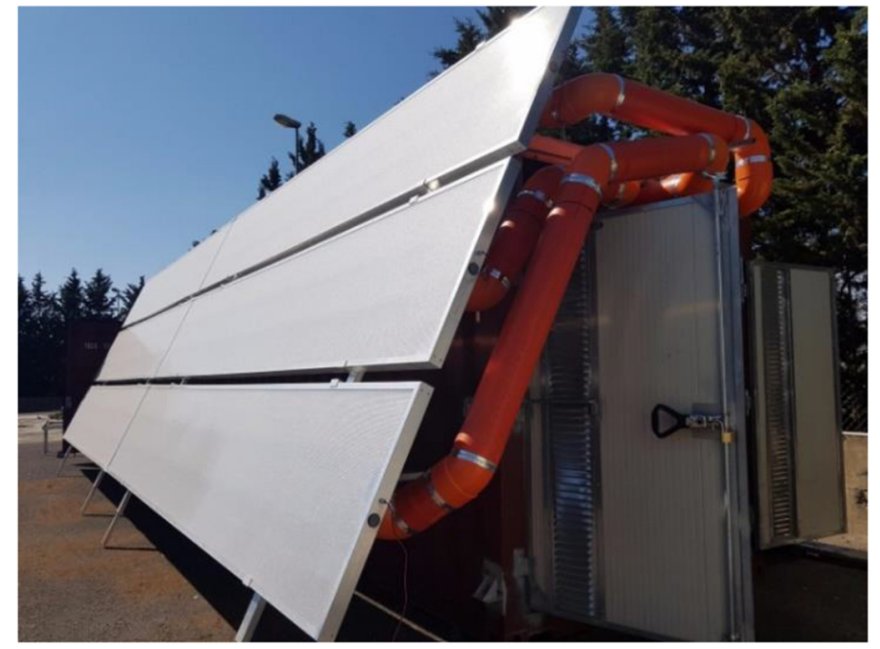

Fig. 2. The solar air dryer system installed at the premises of an agriculture company in San Cono, Sicily, on May 2018.

Based on empirical data collected by the company manufacturing the solar air heating system (monitoring sun irradiation, air temperature and air flow values at different arrays installed in Italy, including Sicily) [26] an average $84 \%$ efficiency is assumed for this system, translating into an expected yearly amount of power supplied by the system amounting to $53,402 \mathrm{~kW}$.

In the third week of May 2018, five tonnes of fresh cladodes obtained by the surrounding OFI plantation (Azienda Agricola Gaetano Spitale, Italy) were cut into $1.5 \mathrm{~cm}$ slices and inserted in the kiln. In this first proof of concept experiment, the hot air in the solar collectors was blown into the kiln using a single fan powered by electricity retrieved from the grid. Humidity and temperatures were closely monitored for five consecutive days until values of relative humidity dropped to $10 \%$.

In general, during the solar day the temperature inside the entire volume of the kiln was around $45^{\circ} \mathrm{C}$ (Fig. 3) whereas the temperature of air leaving the solar collectors during the central hours of the solar day prior to mix with the air inside the kiln may exceed $65^{\circ} \mathrm{C}$.

The cladodes smoothly underwent dehydration. As expected, the process run using solar energy only lasted longer ( 5 days) than that carried out burning natural gas (3 days). The outcomes, however, were stunningly different compared both to conventional drying using natural gas and to direct sun-drying of the cladodes in open environment. Remarkably, indeed, the sun-dried cladodes retained their original green color (Fig. 4).

A closer look to broken cladodes revealed that the color is retained throughout the whole matrix of the dried stems. Accordingly, the chips obtained by grinding the dehydrated stems are deeply coloured in green (Fig. 5).

These findings open the route to the full utilization of the complete mix of biological resources made available by Opuntia cactus plants, most of which reside in its vegetative part.

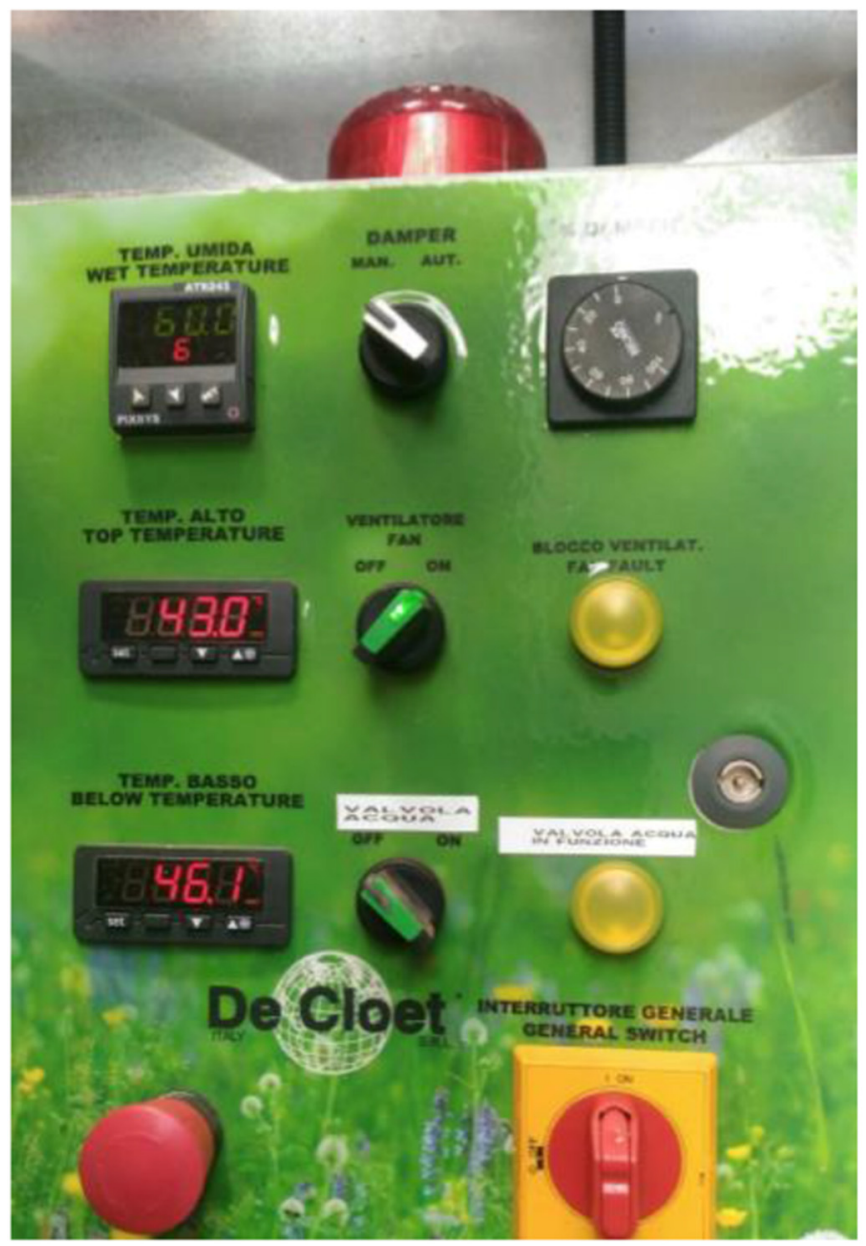

Fig. 3. The control panel of the kiln during the first 5-day dehydration cycle with the solar dryer system installed in San Cono, Sicily.

The integral cellular dehydrate obtained, indeed, retains the green/yellow color likely due to retention of the labile chlorophyll, carotenoids lutein (colored in yellow), $\beta$-carotene (colored in orange) and $\alpha$-cryptoxanthin (red in pure form) molecules, which indirectly points to similar retention of the chemical structure and physicochemical properties of other bioactive molecules present in the cladode cells.

These findings are even more important considering that carotenoids, and not biophenols, are the main antioxidant compounds present in OFI cladodes [27]. Though varying with variety, place of origin, and maturity, on average the total carotenoid content in OFI cladodes is $232 \mathrm{mg} / \mathrm{kg}$ dry basis, corresponding to $46 \%$ lutein, $36 \% \beta$-carotene and $18 \% \alpha$-cryptoxanthin [27].

A forthcoming study will include accurate chlorophyll fluorescence measurements [28], and carotenoid analysis [29] to relate the color to the exact chemical content of dehydrated Nopal cladodes, alongside standard color measurements using the $\mathrm{L}^{*} \mathrm{a}^{*} \mathrm{~b}^{*}$ color scale adopted by the Commission Internationale d'Eclairage (CIE). 

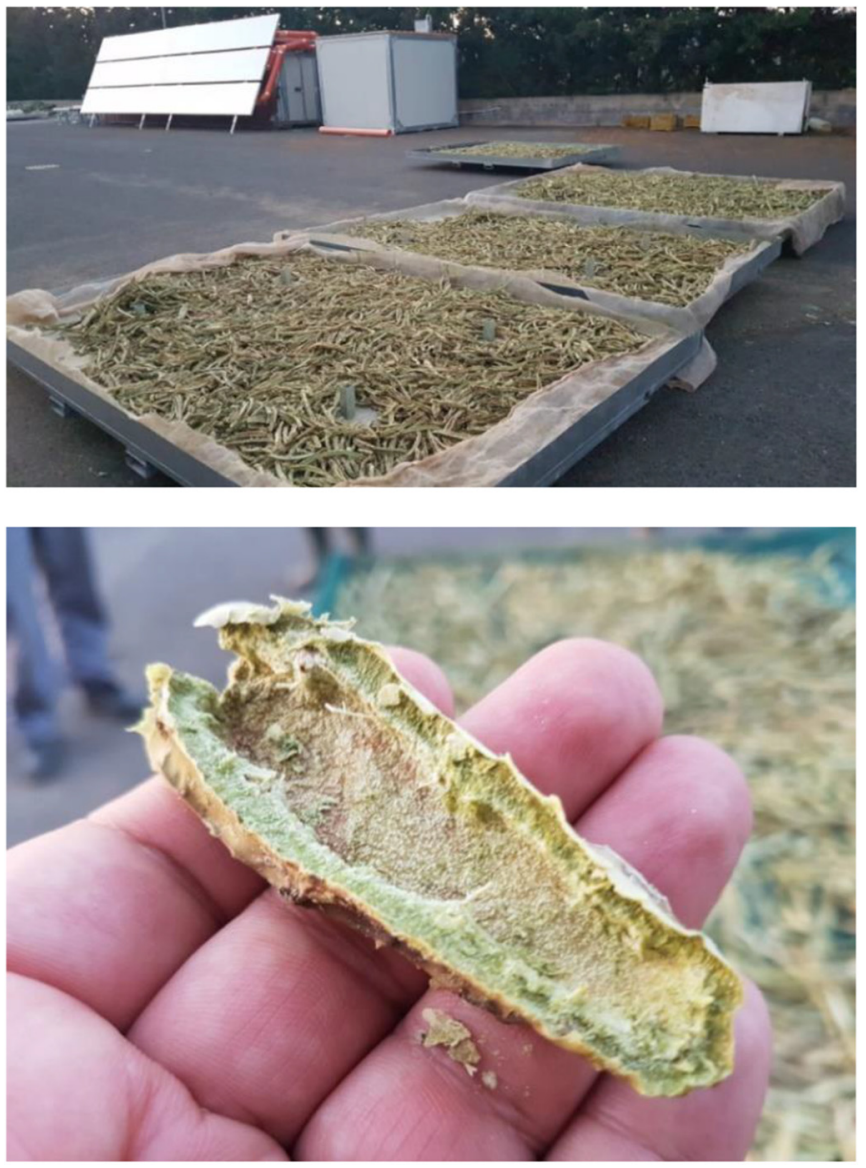

Fig. 4. Sicily's San Cono Opuntia ficus-indica cladodes dehydrated with solar air heating after leaving the kiln (top); and closer look of a dehydrated cladode (bottom).

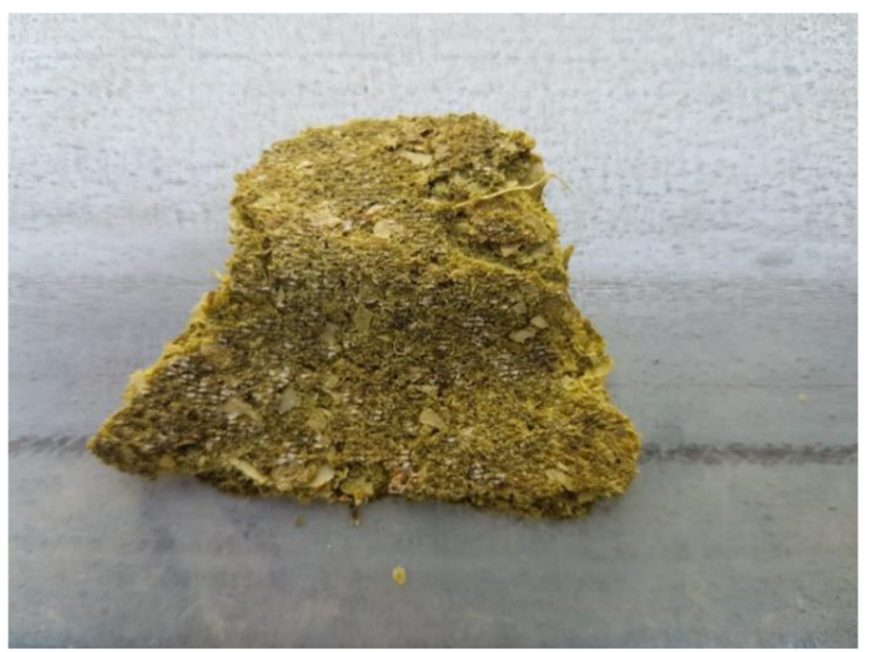

Fig. 5. Chips of Sicily's San Cono Opuntia ficus-indica cladodes dehydrated with solar air heating.

There was no need, in conclusion, to remove part of the protective cuticle to observe a reduction in drying time for the complete cladode drying as it happens with air at $60^{\circ} \mathrm{C}$ generated by electric resistances and fed at a

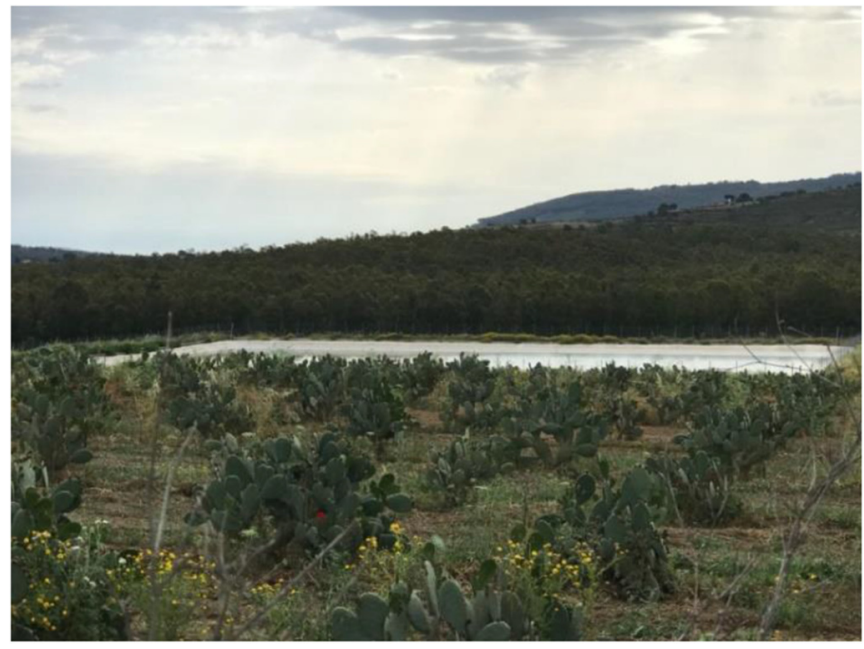

Fig. 6. Artificial lake storing well water and rainwater used to irrigate the Opuntia plantation of present work. All pump energy requirements are met with photovoltaic electricity.

velocity of $1.5 \mathrm{~m} / \mathrm{s}$ when the drying time was $90 \mathrm{~h}$ for the entire cladodes and $65 \mathrm{~h}$ upon removing $30 \%$ of the cuticle [30].

It is also remarkable that the agriculture company from which the Opuntia cladodes were obtained makes a broad utilization of freely available solar energy.

The company, for instance, rather than feeding to the grid the surplus power generated by its $18 \mathrm{~kW}$ photovoltaic array (which also powers an home), uses the surplus to pump well water into a small lake which also stores harvested rainwater (Fig. 6).

Adding to recent findings concerning Sicily's Opuntia' bioeconomy, including seed oil of unique composition [31] and high amounts of valued betanin dye contained in the peel of white and red OFI fruits [32], we have discovered that using solar air heating and ventilation to dehydrate the fresh cladodes of Opuntia ficus-indica produces green dehydrated cladodes and green Nopal powder.

To the best of our knowledge, this is the first report of dried Opuntia spp. cladodes and Nopal which are not brown. Rather than reporting the outcomes of laboratory scale experiments, we carried out the proof of concept experiment in Sicily, Italy, using a $36 \mathrm{~m}^{2}$ solar array to dry 5 tonnes of fresh cladodes cut from the plants a few hours before starting the experiment.

New applications to functionalize foodstuff and to formulate nutraceutical, personal care and cosmetic products of even higher efficacy and broader scope are anticipated. Straightforward separation via reprecipitation of the soluble fraction from the unsoluble fraction of the newly dried Nopal, for example, will make this process an economically viable route to mucilage and low methoxyl pectin, natural hydrocolloids today in large and incressing demand [33].

Similar solar systems are likely to find widespread utilization in all the main Opuntia growing countries, 
including Brazil, Mexico and South Africa whose annual availability of sunlight is comparable or even higher than that of Sicily (Italy's sunniest region).

In forthcoming studies we will report the outcomes of process optimization, including use of PV electricity to power the fan, further reduction in size of the cladode slices, humidity (or moisture content) and temperatures (at the inlet and outlet of the drying chamber) curves as a function of time.

\section{Acknowledgments}

This paper is dedicated to Gaetano Spitale, for all he has done to advance the bioeconomy of Opuntia ficusindica in Sicily and in Italy. We thank Gianmaria Bogino (Solarkup, Italy) for technical information about the solar collectors.

\section{References}

1. Snyman HA (2013), Growth rate and water-use efficiency of cactus pears Opuntia ficus-indica and O. robusta. Arid Land Res Manag 27, 337-348.

2. Guevara JC, Suassuna P, Felker P (2009), Opuntia Forage production systems: status and prospects for rangeland application. Rangeland Ecol Manag 62, 428-434.

3. Azucena Nazareno M (2014), Phytochemicals of nutraceutical importance from cactus and their role in human health, in: D. Prakash, G. Sharma (Eds.), Phytochemicals of Nutraceutical Importance, Cabi, Wallingford, UK, Chapter 7.

4. Yahia EM, Sáenz C (2018), Cactus pear fruit and cladodes, in: E.M. Yahia (Ed.), Fruit and Vegetable Phytochemicals: Chemistry and Human Health, 2nd edition, Wiley, New York, pp. 941-956.

5. Ciriminna R, Chavarría-Hernández N, Rodríguez Hernández A, Pagliaro M (2018), Toward unfolding bioeconomy of nopal (Opuntia spp.). FrenXiv 1. DOI: 10.31226 /osf.io/c89h3

6. Patel S (2014), Opuntia cladodes (nopal): emerging functional food and dietary supplement. Med J Nutr Metab 7, 11-19.

7. Stintzing F, Carle R (2005), Cactus stems (Opuntia spp.): a review on their chemistry, technology, and uses. Mol Nutr Food Res 49, 175-194.

8. Martínez-Soto G, Celis-Fabián F, Hernández-Pérez T, Paredes-López O (2015), Effect of drying methods on the nutraceutical potential of cactus cladodes (Opuntia spp.). Int J Food Nutr Sci 2, 168-173.

9. Ayadi MA, Abdelmaksoud W, Ennouri M, Attia H (2009), Cladodes from Opuntia ficus indica as a source of dietary fiber: effect on dough characteristics and cake making. Ind Crops Prod 30, 40-47.

10. Medina-Torres L, Brito-De La Fuente E, TorrestianaSanchez B, Katthain R (2000), Rheological properties of the mucilage gum (Opuntia ficus indica). Food Hydrocoll 14, 417-424.

11. Cárdenas A, Goycoolea FM, Rinaudo M (2008), On the gelling behaviour of 'nopal' (Opuntia ficus indica) low methoxyl pectin. Carbohydr Polym 73, 212-222.
12. Lynn Buttice A (2012), Aggregation of Sediment and Bacteria with Mucilage from the Opuntia ficus-indica Cactus, PhD Thesis, University of South Florida, Department of Chemical and Biomedical Engineering, See at the URL: http://scholarcommons.usf.edu/etd/4295

13. du Toit A, de Wit M, Hugo A (2018), Cultivar and harvest month influence the nutrient content of Opuntia spp. cactus pear cladode mucilage extracts. Molecules 23,916 .

14. Msaddak L, Abdelhedi O, Kridene A, Rateb M, Belbahri L, Ammar E, Nasri M, Zouari N (2017), Opuntia ficus-indica cladodes as a functional ingredient: bioactive compounds profile and their effect on antioxidant quality of bread. Lipids Health Dis 16, 32.

15. Ginestra G, Parker ML, Bennett RN, Robertson J, Mandalari G, Narbad A, Lo Curto RB,Bisignano G, Faulds CB, Waldron KW (2009), Anatomical, chemical, and biochemical characterization of cladodes from Prickly pear [Opuntia ficus-indica (L.) Mill.]. J Agric Food Chem 57, 10323-10330.

16. Rectamal N, Duran JM, Fernandez J (1987), Seasonal variations of chemical composition in prickly pear (Opuntia ficus-indica (L.) Miller). J Sci Food Agric 38, 303-311.

17. Rocchetti G, Pellizzoni M, Montesano D, Lucini L (2018), Italian Opuntia ficus-indica Cladodes as rich source of bioactive compounds with health-promoting properties. Foods 7, 24.

18. De Santiago E, Domínguez-Fernández M, Cid C, De Pena M-P (2018), Impact of cooking process on nutritional composition and antioxidants of cactus cladodes (Opuntia ficus-indica). Food Chem 240, 1055-1062.

19. Extrasynthese, Opuntia ficus-indica, cladode powder, B0039, https://www.extrasynthese.com/media/extrasynthese/ specifications $/$ B0039.pdf?date $=20171019135910$ (accessed, May 30, 2018).

20. Starwest Botanicals, Nopal Cactus, https://www.starwestbotanicals.com/category/nopal-cactus/ (accessed May 30, 2018). www.amazon.com

21. www.amazon.com. Search conducted on May 30 (2018).

22. Naolys, Foreseen Shield Nopal, www.naolys.com/media/ foreseen_shield_nopal_en.pdf (accessed May 30, 2018).

23. Kumar $\bar{M}$, Sansaniwal $\overline{S K}$, Khatak P (2016), Progress in solar dryers for drying various commodities. Renew Sust Energ Rev 55, 346-360.

24. Ciriminna R, Pecoraino M, Meneguzzo F, Pagliaro M (2017), Solar air heating and ventilation in buildings: a key component in the forthcoming renewable-only energy mix. Energy Technol 5, 1165-1172.

25. Nunes RAX, Costa VC, Sade W, Resende Araújo F, Marconi Silva G (2018), Selective surfaces of black chromium for use in solar absorbers. Mat Res 21, e20170556.

26. Pecoraino M, Bogino G (2015), Heating and healing buildings with solar energy: solar air, in: M. Pagliaro, F. Meneguzzo (Eds.), SuNEC Book of Abstract, Santa Flavia, Sicily, Italy, 9-10 September 2015; PO-6.

27. Jaramillo-Flores ME, González-Cruz L, Cornejo-Mazón M, Dorantes-Alvarez L, Gutiérrez-López GF, HernándezSánchez H (2003), Effect of thermal treatment on the antioxidant activity and content of carotenoids and phenolic compounds of cactus pear cladodes (Opuntia ficus-indica). Food Sci Technol Int 9, 271-278. 
28. Arias-Moreno DM, Jiménez-Bremont JF, Maruri-López I, Delgado-Sánchez P (2017), Effects of catalase on chloroplast arrangement in Opuntia streptacantha chlorenchyma cells under salt stress. Sci Rep 7, 8656.

29. Cano MP, Gómez-Maqueo A, García-Cayuela T, WeltiChanes J (2017), Characterization of carotenoid profile of Spanish Sanguinos and Verdal prickly pear (Opuntia ficus-indica, spp.) tissues. Food Chem. 237, 612-622.

30. Lopez R, De Ita A, Vaca M (2009), Drying of prickly pear cactus cladodes (Opuntia ficus indica) in a forced convection tunnel. Energy Convers Manag 50, 2119-2126.
31. Ciriminna R, Bongiorno D, Scurria A, Danzì C, Timpanaro G, Delisi R, Avellone G, Pagliaro M (2017), Sicilian Opuntia ficus-indica seed oil: Fatty acid composition and bioeconomical aspects. Eur J Lipid Sci Technol 119, 1700232.

32. Ciriminna R, Danzì C, Timpanaro G, Locatelli M, Carnaroglio D,Fidalgo A, Scurria A, Avellone G, Ilharco LM, Pagliaro M (2017), Valued bioproducts from waste Opuntia ficus-indica peel via microwave-assisted hydrodiffusion and hydrodistillation. Preprints 2017100145 (doi: 10.20944/preprints201710.0145.v1).

33. Ciriminna R, Chavarría-Hernández N, Rodríguez Hernández A, Pagliaro M (2015), Pectin: a new perspective from the biorefinery standpoint. Biofuel Bioprod Bior 9, 368-377.

Cite this article as: Ciriminna R, Morreale V, Pecoraino M, Pagliaro M. (2019), Solar air drying for innovative Opuntia ficusindica cladode dehydration. 4open, $\mathbf{2}, 1$. 